\title{
Knowledge Creation in State-owned Enterprises
}

\author{
Maxim Vlasov \\ Ural Federal University named after the first President of Russia B.N.Yeltsin, Ekaterinburg, Russia, \\ Senior Fellow at the Centre of Economic Theory, Institute of Economics, \\ Ural Branch of the Russian Academy of Sciences, Ekaterinburg \\ Email: Mvlassov@mail.ru

\section{Svetlana Panikarova} \\ Ural Federal University named after the first President of Russia B.N. Yeltsin, Ekaterinburg, Russia, \\ Senior Fellow at the Centre of Economic Theory, Institute of Economics, \\ Ural Branch of the Russian Academy of Sciences, Ekaterinburg \\ Email: panikarova_s@mail.ru
}

\section{Doi:10.5901/mjss.2015.v6n4p475}

\section{Abstract}

The special part in economy of knowledge is assigned to the hi-tech industry. Russian hi-tech industry includes primarily stateowned enterprises, whose purpose is the execution of the state order. According to the statistic, a large part of scientificresearch and experimental-design works is produced during execution of the state order. Therefore, the main research question the following: how to estimate efficiency of knowledge creation at the state-owned enterprises. The purpose of the present study was to provide a methodology for assessment of the knowledge creation efficiency at the state-owned enterprises. This methodology was been based on measurement of the coefficient of intellectual share of the profits. This coefficient was calculated as change of the intellectual capital divided by change of profit. Relevance of research objectives is caused by need of optimization of the budgetary expenses on research and development. The article takes an eclectic methodological approach to piece together extant literature and to discover new empirical knowledge about knowledge creation. For estimation of the knowledge creation efficiency, authors use the data of intellectual capital (scientific publishing and inventive activity) during 2005-2013 at the state-owned Russian enterprise and compares them with data of expenses on research and development. Authors also carried out 10 in-depth interviews with experts from different innovative state-owned enterprises for understanding of features of knowledge management at the state enterprises. The theoretical importance of the conducted research is expansion of the methodological device of knowledge economy. The empirical results of the research confirm the fact the coefficient of intellectual share of the profits is the useful operational instrument for the strategic planning in innovative state-owned enterprises. In addition, the results of analysis using coefficient of intellectual share of the profits indicated that the change of the budgetary $R \& D$ expenses caused by a phase of a business cycle had a direct effect on knowledge creation efficiency. The research demonstrates the methodology for assessment of the knowledge creation efficiency can become the effective instrument of development of state innovative policy.

Keywords: knowledge creation, intellectual capital, state-owned enterprises.

\section{Introduction}

\subsection{Problem statement}

The development in the XXI century is characterized by the growth of high-tech industries and knowledge-intensive technologies. It has caused a transition to a new qualitative level of development of knowledge economy. It is type of economy, where the main growth factors are knowledge and human capital. Development of knowledge economy includes such elements as improving the quality of human capital in the knowledge production of high technology, innovation and high quality services. Russian hi-tech industry includes primarily state-owned enterprises, which produce a large part of scientific-research and experimental-design works according to the statistic.

The purpose of the present study is to provide a methodology for assessment of the knowledge creation efficiency at the state-owned enterprises. 


\subsection{Analysis of the main publications}

The recognition of knowledge for the success of the organization and the need to take advantage of them, has led some researchers to propose methods that are useful to manage this high-value knowledge efficiently (Dangelico, 2008; Karami, 2006; Kurtossy, 2004; Nonaka, 2007; Garengo et al, 2005; Gold et al, 2001). In scientific literature, the problem of evaluation of knowledge creation at industrial enterprises devoted a lot of attention. Various methods of determining the effectiveness of the new knowledge was considered by Malkova A. (2012), I. Pogorelskaya T. (2009), Dudyasova V., Kipel N., Smirnova E. (2012). The authors Bocharova M. A. and Kouzmina A. A. (2010) proposed to use the value of intellectual capital for the evaluation of the system of knowledge generation at industrial enterprises. Nonaka and Toyama (2005) developed dynamic models that allow the development of capacities to transfer and combine knowledge in companies. Jugdev (2007) proposed that the companies most likely to achieve successful innovation would be those that are able to learn how to create, transfer and manage knowledge. Existing studies indicated that state ownership could stifle innovation and R\&D in firms (Berliner, 1976). Some theoretical work showed that R\&D activities in state-owned sectors were less efficient than those were in private sectors (Qian\&Xu, 1998; Zhang and all, 2003).

Although there is extensive literature focused on the features of knowledge creation in state-owned enterprises, there is not an adequate approach to develop a methodology for measuring of the knowledge creation efficiency at the state-owned enterprises.

The structure of the paper is as follows: The second section presents the methodology for assessment of the knowledge creation efficiency. The third characterizes the results of the empirical research of the knowledge creation efficiency at the state-owned enterprises. The forth section is the conclusion.

\section{Methodology}

\subsection{Review of the existing methods}

Activity of knowledge generation is not only the process of creating knowledge, but also is the process of knowledge accumulation, distribution and diffusion. In addition, knowledge generation includes knowledge consumption, transfer, knowledge sharing, as well as the types of changed resources (Vlasov, 2015).

We consider the existent methods of evaluation of knowledge generation in enterprises and determine the applicability of these methods in state-owned enterprises.

Method of evaluating the effectiveness of the system of production of new knowledge by Malkova A. (Malkova, 2012) consists of two indicators:

- average citation count per article;

- cost spending on the one article divide by the citation count per article.

The disadvantage of this method is absence of attention to influence of R\&D activities on firm performance.

Method of evaluation of effectiveness, intensity and rapidity

According to research conducted by Pogorelskaya T. (Pogorelskaya, 2009) the efficiency of knowledge management system can be assessed as a combination of three indicators: effectiveness, intensity and rapidity. Effectiveness of the knowledge management system is defined ability of system to achieve strategic goals of the enterprise. Intensity is set of the general expenses of the resources (information, labor, financial etc.) used for receiving target effect of the knowledge management system. The rapidity of the knowledge management system is the consumption of time required to achieve this goal.

The generalized criterion of knowledge management efficiency represents in the following formula 1:

$E=P \cdot a_{P}+P_{E} \cdot a_{P E}+0 \cdot a_{0}$,

where $\mathrm{P}$ - the effectiveness indicator of the knowledge management system; $\mathrm{PE}_{\mathrm{E}}$ - measure the intensity of the system; $\mathrm{O}-$ the indicator the rapidity of the system; $\mathrm{a}_{\mathrm{P}}, \mathrm{a}_{\mathrm{PE}}, \mathrm{a}_{\mathrm{O}}$ - the importance of indicators, while achieving the specific goals of knowledge management.

The effectiveness of the knowledge management system is the ratio of the achieved results to the desired target criterion. The measure of the intensity of the system defines as the ratio of the resources expended per unit of outcome. The rapidity of the system reflects speed of reaction to change of external conditions.

This method of evaluation of knowledge generation has the following disadvantages:

- the lack of specific criteria for the assessment of effectiveness, intensity and rapidity for large enterprises (including the state-owned enterprises);

- does not take into account the results of innovative activity and the creation of inventions. 
The method of complex intangible assessment of knowledge creation by Bocharova, M. and Kouzmina A (Bocharova\&Kouzmina, 2010). This evaluation consists of three steps:

- calculation of the intellectual capital (Tobin tax);

- calculation of the coefficient of influence of intellectual capital on financial performance by formula 2 :

$R_{\text {change }}=\Delta \mid A / \Delta$ Profit,

where $\mathrm{R}$ change - the coefficient that characterizes as change of the intellectual capital influences firm performance; $\Delta \mathrm{IA}$ - difference between the value of intellectual capital before and after the organization of knowledge management system; $\Delta$ Profit - difference between the profit before and after the organization of knowledge management system.

- calculation of the intangible assets monitor developed by K.E. Sveiby (Sveiby, 1997).

The main disadvantage of this method is absence of attention for changing specific components resulting from the organization's knowledge management.

Method of evaluation of knowledge increase.

The method by Dudasova V., Kipel N., Smirnova E. (Dudasova et al, 2012) involves the calculation of the efficiency index of knowledge increase ( $\left.E^{G K}\right)$ that is calculated by the formula 3 :

$E^{G K}=I R$ GK $/ I C C^{G K} \times 100 \%$,

Where IR ${ }^{G K}$ - the index is the average level of the knowledge increase in organization; IC GK - the index of the costs of increase in workers' knowledge.

The efficiency index of knowledge increase characterizes not only the efficiency of the activities for the production and exchange of knowledge, but also its efficiency, i.e. achieving a given level with minimal cost. However, this indicator does not take into account the time factor, which is a key factor when state-owned enterprises are performing a public order.

Cost-effectiveness method of evaluation of knowledge generation.

This method by Dudyasova B. and Kipel N. (Dudasova\& Kipel, 2013) bases on the measuring of natural and valuable indicators. Natural indicators include the volume (in hours), the level of learning (in marks), capacity (in megabytes) and other. Valuable indicators include primary, restorable, residual value. The primary value is calculated as the sum of total expenditure on the acquisition of knowledge from external and internal sources. The restorable value is calculated taking into account the current market prices of knowledge obtained from external and internal sources. The residual value of knowledge ( $\left.\mathrm{CK}_{\text {res }}\right)$ is the difference (in rubles) between the primary cost $\left(\mathrm{CK}_{\mathrm{i}}\right)$ or restorable cost ( $\left.\mathrm{CK}_{\text {rec }}\right)$ and the amount of commercial obsolescence $\mathrm{CO}$, is calculated by formula 4:

$\mathrm{CK}_{\text {res }}=\mathrm{CK}_{\mathrm{i}}\left(\mathrm{CK}_{\text {rec }}\right)-\mathrm{CO}$

Commercial obsolescence of knowledge is part of knowledge value, which is transferred to product cost by depreciation charge. The commercial obsolescence of knowledge is defined in the same manner as the commercial obsolescence of fixed assets (formula 5):

$$
C O=\frac{R D}{100} * P A U^{*} C K_{\text {res }} \text {, }
$$

where $\mathrm{RD}$ - the rate of depreciation (\%); PAU - the period of actual use of knowledge (years).

This is one of the few methods of evaluation, which has a value expression, but does not measure organizational knowledge, does not take into account all factors of intellectual capital.

After analyzing the literature, the authors conclude that there is no single system of evaluation of knowledge generation. The authors conduct an empirical study of the applicability of the coefficient changes as the most appropriate assessment of knowledge generation in state-owned enterprises.

\subsection{Authors' method}

Author's method is based on measurement of the coefficient of intellectual share of the profits. This coefficient is change of the intellectual capital divided by change of profit, according to the formula 6 :

$K_{\mathbb{P}}=\Delta I K / \Delta P$,

Were $K_{I P}$ - rate of intellectual profit share; $\Delta \mathrm{IK}$ - changing the value of intellectual capital; $\Delta \mathrm{P}$ - changing of profit.

Feature of a method is calculation of the period in one calendar year, but not from the moment of introduction of a system of knowledge management. This approach considers instability of an economic situation in Russia and need of development of the instant solution, which are adequately answering to external economic changes.

To ensure clarity of the results obtained, evaluation conducts on each of the stages of the product lifecycle:

1. Research, marketing;

2. Specification, modeling; 
3. The development of the scheme, the software;

4. Development engineering and technological documentation;

5. The manufacture of the product;

6. Testing, supervision.

The profit and the size of the intellectual capital are normalized taking into account inflation. As a result, the data in the form of a relative profit growth and a relative growth of the intellectual capital is received.

\section{Results and Discussion}

Authors approve a method on data of one of leading enterprises of Russia in the field of development and production of an automation equipment of technological processes in various industries. This enterprise provides a full production cycle of creation of original automated technical process management systems and complexes. More than 4000 people work at the studied enterprise; more than a half of employees are occupied in research and development.

The coefficient of intellectual share of the profits calculates for estimation of the knowledge creation efficiency. Authors use the data of intellectual capital (scientific publishing and inventive activity) during 2005-2013 at the stateowned enterprise and compares them with data of expenses on research and development. Authors also carried out 10 in-depth interviews with experts from different innovative state-owned enterprises for understanding of features of knowledge management at the state enterprises.

Rate K IP is calculated for the period from 2005 to 2013, the obtained data are presented in table 1.

Table 1. The rate intellectual profit share 2005-2013

\begin{tabular}{|c|c|c|c|c|c|c|c|c|c|}
\hline & 2005 & 2006 & 2007 & 2008 & 2009 & 2010 & 2011 & 2012 & 2013 \\
\hline & & & & & & & & & \\
\hline$\Delta \mathrm{IK}$ & 1 & $-0,22$ & 0,857 & 0,885 & $-0,16$ & 0,48 & $-0,57$ & 0,462 & 0,605 \\
\hline & & & & & & & & & \\
\hline$\Delta \mathrm{P} *$ & 1 & 0,261 & 0,438 & 0,136 & 0,155 & 0,026 & 0,025 & 0,162 & 0,07 \\
\hline & & & & & & & & & \\
\hline $\mathrm{K}_{\mathrm{IP}}$ & 1 & $-0,85$ & 1,955 & 6,52 & $-1,03$ & 18,8 & $-22,6$ & 2,841 & 8,601 \\
\hline
\end{tabular}

* $T o$ the prices 2013, according to the refinancing rate of the CBR 2005-2012

Because of estimated figures, the authors have constructed a graph showing the dependence of the growth in profit from changes in intellectual capital (figure 1).

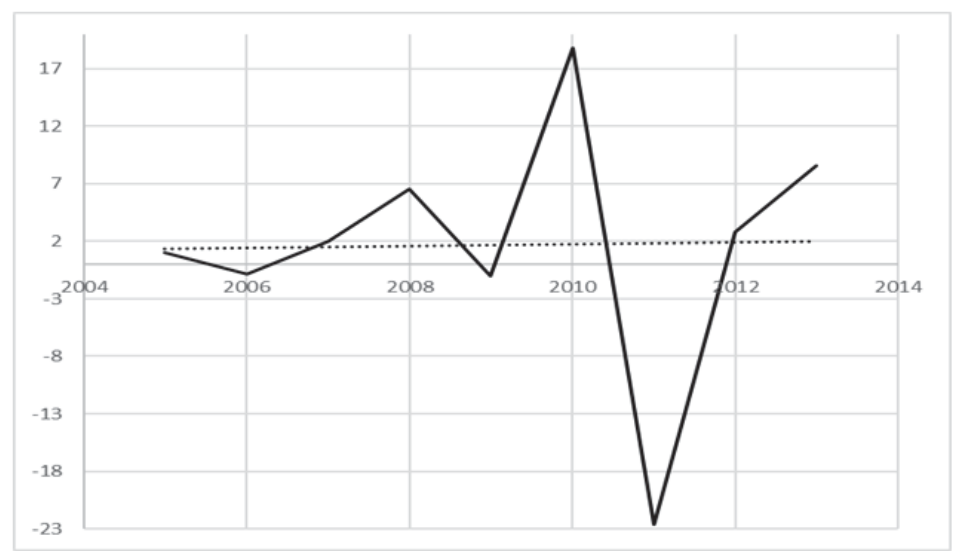

Figure 1. The coefficient intellectual profit share 2005-2013

System interpretation of the slope of the trend line of rate of intellectual profit share. Figure 2 shows the possible options for the angle of the trend line of rate of intellectual profit share. 


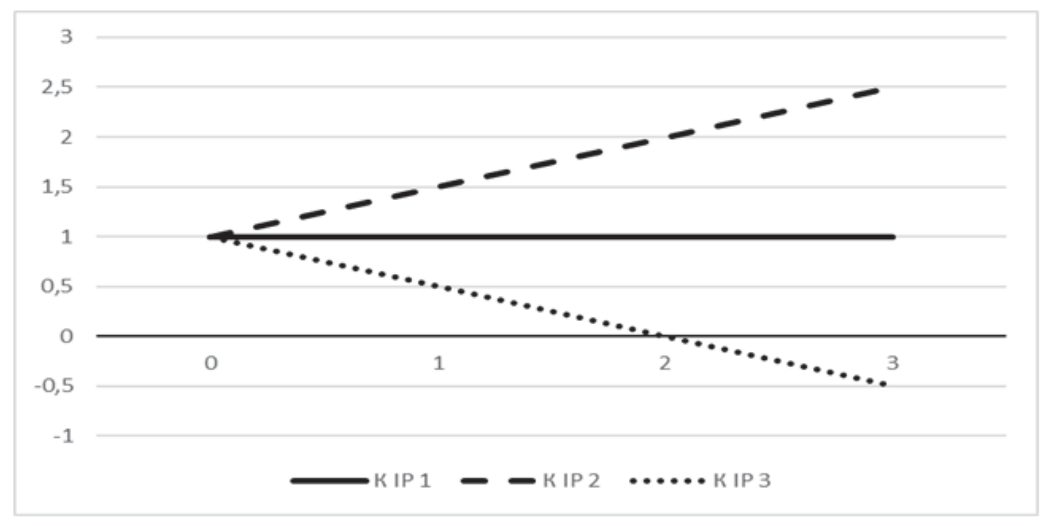

Figure 2. Options for the angle of the trend line $K_{I P}$

1. If profit markup is caused by growth of the intellectual capital, the tilt angle of the line of a trend of KIP is the positive. In this situation, the pace of profit growth exceeds the growth rate of investment in intellectual capital.

2. If investments in the intellectual capital provide constant profit level, a tilt angle the line of a trend of KIP there is a zero. In this situation does not have safety reserve therefore external factors can strongly influence growth/decrease in profit of the enterprise.

3. If change of the intellectual capital does not cause the corresponding profit markup, the line of a trend of KIP has a negative tilt angle. In this case, the profit of the enterprise has a tendency to decline.

Figure 1 shows the positive slope of the trend line of rate of the coefficient of intellectual share of the profits. Thus, growth rates of profit exceed growth rates of investments in the intellectual capital at the studied large innovative stateowned enterprise. However, the small tilt angle testifies to low efficiency of investment into knowledge generation.

Sharp decrease in coefficient in 2009 is caused by a consequence of world financial crisis. Sharp decrease in coefficient in 2011 is caused by decrease in the budgetary financing and outflow of the research personnel. The program of development of publishing activity and scientific mobility is required for increase of dynamics of a gain of the intellectual capital.

\section{Conclusions}

The study aimed at the development of methodological tools for quantitative assessment of the processes of knowledge generation in state-owned enterprises allowed to obtain the following theoretical and practical results.

Firstly, authors offer the coefficient of intellectual share of the profits for a quantitative assessment of efficiency of activities for knowledge generation at the state-owned enterprise.

Secondly, authors offer the system of interpretation of indicators of productivity of activities for generation knowledge at the state enterprise.

The theoretical importance of the conducted research is expansion of the methodological device of knowledge economy. The empirical results of the research confirm the fact the coefficient of intellectual share of the profits is the useful operational instrument for the strategic planning in innovative state-owned enterprises. In addition, the results of analysis using coefficient of intellectual share of the profits indicated that the change of the budgetary R\&D expenses caused by a phase of a business cycle had a direct effect on knowledge creation efficiency. The research demonstrates the methodology for assessment of the knowledge creation efficiency can become the effective instrument of development of state innovative policy.

\section{Acknowledgement}

The study was sponsored by Russian Foundation for Humanities grant RFH № 15-02-18003 Experimental study of the impact of competitive financing of scientific activity. 


\section{References}

Berliner, Joseph S. (1976). The Innovation Decision in Soviet Industry. MIT Press, Cambridge, MA.

Bocharova, M. A. and Kouzmina A.A. (2010) Approaches to an assessment of system effectiveness of management of knowledge of the modern organization//Transport business of Russia. 2010. No. 9. pp. 162-165.

Dangelico, R. M. et al. (2008) Knowledge Creation and Transfer in Local Global Technology Networks: A System Dynamics Perspective, International Journal of Globalization and Small Business, Vol. 2, No. 3, pp. 300-324

Dudyasova V.P., Kipel N.A., Smirnova E.A. (2013) The account and assessment of organizational knowledge at the enterprise//The Siberian financial school. 2013. No. 1 (96). pp. 75-77.

Dudyasova V.P., Kipel N.A., Smirnova E.A. (2012) Assessment of efficiency of an increment of knowledge of the self-training organization//News of higher educational institutions. Series: Economy, finance and production management. 2012. No. 2. pp 8186.

Garengo, P., Biazzo, S. and Bititic, U. (2005). Performance measurement systems in SMEs: A review for a research agenda, International Journal of Management Reviews, Vol. 7, No. 1, pp. 25-47

Gold, A., Malhotra, A. and Segars, A. (2001). Knowledge Management: An Organizational Capabilities Perspective, Journal of Management Information System, Vol. 18, No 1, pp. 185-214

Jugdev, K. (2007). Closing the Circle: The Knowledge Management Spiral of Project Management, International Journal of Knowledge Management Studies, Vol. 1, No 3/4, pp. 423-441

Karami, A., Rowley, J., Analoui, F. (2006). Research and Knowledge building ion Management Studies: An Analysis of Methodological References, International Journal of Management, Vol. 12, No 3, pp. 24-29

Kurtossy, J. (2004). Innovation Indicators Derived from Patent Data, Periodica Polytechnica Ser. Cos. Man. SCl, Vol. 12, No 1, pp. 99101

Malkova A.A. (2012) Evaluation of the effectiveness of the production of new knowledge // Innovation Management: Theory, methodology, practice. 2012. № 2. pp 215-220.

Nonaka, I. (2007). The Knowledge Creating Company, Harvard Business Review, July-August

Nonaka, I. and Toyama, R. (2005). The Theory of the Knowledge Creating Firm: Subjectivity, Objectivity and Synthesis, Industrial and Corporate Change Vol. 14, No 3, pp. 419-436

Pogorelskaya T. A. (2009) Knowledge management system of the enterprise: the problem of constructing and evaluating the effectiveness // Terra Economicus. 2009. T. 7. № 3-3. pp. 163-165.

Sveiby, K.E. (1997). The New Organizational Wealth - Managing and Measuring Knowledge-Based Assets, Berrett-Koefler, SanFrancisco, SA

Qian, Yingyi, Xu, Chenggang. (1998). Innovation and bureaucracy under soft and hard budget constraints, Review of Economic Studies, No 65 , pp. 151-164

Vlasov, M.V. (2015). Knowledge Generation Managing at Universities. Mediterranean Journal of Social Sciences. Vol 6, No 1, pp. 453458

Zhang, A., Zhang, Y., Zhao, R. (2003). A study of the R\&D efficiency and productivity of Chinese firms, Journal o0f Comparative Economics, No. 31, pp. 444-464 